\title{
Las atarazanas de Barcelona: fábrica de galeras de la Monarquía (I599-I748)
}

\author{
Alfredo Chamorro Esteban ${ }^{*}$ \\ Museu Marítim de Barcelona
}

\section{Resumen}

En el presente texto se realiza una aproximación al estudio de las Reales Atarazanas de Barcelona en los siglos XVII y XVIII. Durante este tiempo, las atarazanas desempeñaron su actividad constructora de galeras, hasta su definitivo cierre como astillero en I746. En el siguiente artículo se abordan diversos aspectos importantes para el conocimiento de la institución: su evolución histórica durante este período, qué producción de buques hubo, cómo se hicieron, qué materiales se utilizaron o de qué tipo eran los profesionales que participaron en la construcción naval. Todos ellos estuvieron condicionados por la situación política, económica y social del momento, lo que pudo facilitar o dificultar su existencia como fábrica de galeras de la Monarquía.

Palabras clave: atarazanas, galeras, fábrica, Barcelona, madera, maestranza.

\section{Les Drassanes Reials de Barcelona: fabrica de galeres de la monarquia (1599-1748)}

\section{Resum}

En el present text es fa un apropament a l'estudi de les Reials Drassanes de Barcelona als segles XVII i XVIII. Al llarg d'aquest temps, les Drassanes conti-

* Este artículo se ha realizado gracias a la financiación de la Fundació de Suport al Museu Marítim i Drassanes Reials de Barcelona, en cuyo proyecto de investigación se enmarca este trabajo. 
nuaren la seva activitat constructora de galeres fins al seu tancament definitiu l'any 1746. L'article aborda diversos aspectes importants per al coneixement de la institució: la seva evolució històrica durant aquest període, quina fou la producció de bucs i com es feien, quins materials s'utilitzaven o quin tipus de professionals participaven en la construcció naval. Tots aquests aspectes estigueren condicionats per la situació política, econòmica i social del moment, cosa que pogué facilitar o dificultar l'existència de les Drassanes com a fabrica de galeres de la monarquia.

Paraules clau: drassanes, galeres, fabrica, Barcelona, fusta i mestrança.

The Royal Shipyards of Barcelona: the galley shipyard of the Spanish Monarchy (1599-1748)

\section{Abstract}

This paper deals with the study of the Royal Shipyards of Barcelona in the 17 th and I8th centuries. During this time the Shipyards continued with the construction of galleys until its final closure in 1746. The following article addresses several aspects of the institution: its historical evolution during this time, what ship production there was, how the ships were made, which materials were used, and what kind of professionals participated in shipbuilding. All these aspects were conditioned by the political, economic and social situation of the time, which could facilitate or hinder the Shipyards' existence as a builder of galleys for the monarchy.

Keywords: shipyard, galleys, factory, Barcelona, wood and shipbuilders.

Las Reales Atarazanas entraron en el siglo XvII a pleno funcionamiento, favorecida su actividad por la presencia del rey en Barcelona y la celebración de Cortes el último año del siglo anterior. En I6oo se estaban fabricando en el astillero catalán ocho galeras simultáneamente. Pese a que dista mucho de las grandes producciones de galeras de las décadas de I550 y I560, este número es indicativo de que, mejor o peor, las atarazanas continuaban con su actividad fabril a inicios del reinado de Felipe III, y es el objetivo de este artículo averiguar si dicha producción tuvo con- 
tinuidad a lo largo del siglo XVII. Así, en el siguiente texto trataremos de responder a esta pregunta, y para ello, por un lado, reconstruiremos la historia de las Reales Atarazanas de Barcelona durante este período, hasta ahora, todavía desconocida - como se ha advertido en el artículo de Enric Garcia e Inma González, que forma parte de este dosier-, y por el otro, analizaremos las vicisitudes del proceso de construcción y botadura - la documentación de la época utiliza el verbo varar para referirse a esta última acción — de las galeras. En este sentido, hemos planteado el estudio de las atarazanas de Barcelona a partir de seis aspectos.

En primer lugar, nos centraremos en la evolución histórica de la institución y del edificio en época moderna. Iniciamos el estudio en I599, año en que Felipe III realizó Cortes en Barcelona, al comienzo de su reinado, y lo finalizamos en $\mathbf{1 7 4 6}$, fecha en la que, por real cédula, se ordenó el cese de la actividad de las Reales Atarazanas y que toda la maestranza pasase a Cartagena, base principal de las galeras en el Mediterráneo. Por lo tanto, esta investigación abarca un periplo cronológico de casi ciento cincuenta años, en los que ya podemos avanzar que hubo actividad fabril, con la excepción de los dos períodos bélicos: la guerra de los Segadores (I640-I652), aunque la inactividad perduró hasta I664, y la guerra de sucesión (I705-I7I4). Durante todo este tiempo, el astillero barcelonés constituyó el principal, y único, centro productor de galeras de la península ibérica, si bien era complementado con las producciones de los centros italianos —Génova, Mesina y Nápoles_-, cuyos buques iban destinados sobre todo a sus respectivas escuadras de galeras. Las fabricadas en Barcelona, en cambio, solían botarse para que se integraran en la escuadra de galeras de Espańa, aunque en ocasiones hallamos buques destinados a otras escuadras.

En segundo lugar, veremos algunos aspectos relacionados con la financiación de la construcción de las galeras y con las dos opciones que había — como explicaremos más adelante_ para hacerlo: por administración o por asiento.

El tercer aspecto que trataremos es el referente a la producción de buques en las atarazanas, es decir, la capacidad productiva del astillero y algunas de las dificultades que encontraron sus oficiales para llevar a cabo su construcción. 
En cuarto lugar, nos centraremos en las técnicas de construcción, en su mayoría bastante desconocidas por la falta de tratados. Las medidas que debían tener los buques y su botadura al agua son aspectos interesantes de su producción.

En quinto lugar abordaremos el estudio de los materiales necesarios para la construcción naval, en especial, la madera. Su origen geográfico y la tala y transporte de los árboles desde los bosques hasta las atarazanas son elementos básicos para saber qué incidencia tenía la actividad fabril del astillero en el hinterland de Barcelona y más allá.

Por último, es necesario tratar la maestranza que trabajaba en las atarazanas, en concreto, maestros de azuela y calafates. Estos profesionales eran indispensables para la construcción naval y era, por lo tanto, la base de la estructura productiva, como se verá en el artículo.

En definitiva, estos seis aspectos aquí tratados muestran una visión de la historia de las atarazanas en época moderna que se ajusta a los parámetros establecidos por el proyecto del Museo Marítimo de Barcelona.

\section{Una historia poco conocida}

En el siglo XVII, la gestión de las Reales Atarazanas había cambiado de forma sustancial. La administración tripartita de la institución, vigente durante el período bajomedieval y buena parte del siglo XVI, en la que coexistían tres drassaners — uno real, otro de la Diputación y otro del Consejo de Ciento—, ${ }^{1}$ derivó en el mandato único del superintendente de las atarazanas, heredero del oficio de drassaner real. La gestión de la institución en estas fechas era, exclusivamente, tarea suya, y lo hacía en nombre del rey. Por otro lado, sí que encontramos a lo largo de todo el siglo la figura del drassaner del General, eso sí, limitadas

I. Sobre la coexistencia de estos tres drassaners en época medieval, véase Albert Estrada-Rius, La Drassana Reial de Barcelona a l'Edat Mitjana: organització institucional i construcció naval a la Corona d'Aragó, Museu Marítim de Barcelona, Barcelona, 2004, pp. 35-64. 
sus funciones a la gestión del edificio o almacén que la Diputación tenía adyacente a las atarazanas y a la supervisión de las obras sufragadas por la propia institución. Tuvo algo más de relevancia durante las dos primeras décadas del siglo XviI, mientras la Diputación tuvo la pequeña escuadra de cuatro galeras que Felipe III les permitió mantener tras las Cortes de $1599 .^{2}$ Pese a que era un cargo designado por los diputados, el oficio de drassaner podía venderse, lo que no ocurría con el de superintendente. Así, casi todos los nombramientos que se produjeron en el siglo XVII vinieron precedidos de una venta del cargo del titular a un interesado por adquirirlo. Sin embargo, nada sabemos del drassaner de la Ciutat, lo que hace pensar que el Consejo de Ciento tuvo poco peso político en la institución durante estos años, cuando, además, la ciudad ya no poseía galeras.

Por tanto, el superintendente era la máxima autoridad de las atarazanas. Nombrado directamente por el rey, sus funciones eran múltiples. Solía ser una persona con amplios conocimientos de navegación en el mar y con experiencia en las galeras. Gestionaba la producción y administraba la institución; ejecutaba las órdenes del rey, que recibía a través del virrey de turno o de los secretarios reales; se encargaba de administrar los caudales y las consignaciones; inspeccionaba los bosques y plantíos en busca de los árboles más adecuados y supervisaba la tala y conducción de los mismos hasta las atarazanas; mantenía contacto con los oficiales de las galeras; informaba del estado de las construcciones y, entre otras muchas funciones, reclutaba y mandaba a la maestranza. En fin, en la buena gestión del superintendente descansaba el éxito de la construcción de galeras. Sus tareas y responsabilidades eran muy numerosas y, por este motivo, su capacidad y actitud debían ser intachables.

Durante los primeros años del siglo Xviı, el superintendente de las atarazanas fue don Ramon d'Oms (I593-I608). Preguntado por el Consejo de Aragón, en relación con la elección de capitán general para la

2. John H. Elliott, La revolta catalana. Un estudi sobre la decadència d'Espanya, Publicacions de la Universitat de València, Valencia, 2006 [ed. or., 1963], p. 70. 
escuadra de galeras de Cataluña, el virrey del Principado, duque de Feria, dijo sobre él:

Don Ramon Doms que ha andado en la mar y dado buena quanta de si, y ha visto hablar bien del a todos los que de aquel tiempo lo conocieron, y que agora es superintendente de las galeras que se hacen en las Atarazanas de Barcelona y que de aquello y de todo lo demás que le ha encargado ha dado siempre mucha satisfacion. ${ }^{3}$

A lo largo de su mandato se construyeron numerosas galeras en el astillero barcelonés. Sin embargo, tuvo que hacer frente a una fuerte crítica sobre la calidad de las embarcaciones, ya que, según el capitán general de las galeras de España, conde de Santa Gadea, y sus oficiales, las ocho galeras que se botaron al mar en 1600 tenían algunos defectos importantes que dificultaban la navegación. ${ }^{4}$ Ante esta situación, don Ramon d'Oms y los maestros mayores de galeras, máximos responsables de la construcción de las naves, defendieron la calidad de los buques salidos de las atarazanas y denunciaron la falta de destreza de los oficiales de las galeras como causa de su escasa maniobrabilidad, además de acusarlos de querer acabar con el astillero. ${ }^{5}$ Tras esta polémica, subyacía un debate en torno al modelo económico más adecuado para la construcción y el mantenimiento de las galeras: por administración o por asiento. El primero, había sido el modelo utilizado en la construcción de galeras en las Atarazanas de Barcelona durante buena parte del siglo XVI, mientras que el segundo se había hecho preponderante durante las dos últimas décadas de ese mismo siglo, en especial en todo lo referente al aprovisionamiento del ejército —incluidas las escuadras de galeras de la Monarquía- y a la construcción de naos, navíos y otras

3. Archivo de la Corona de Aragón (ACA), Consejo de Aragón (CA), leg. 270, núm. IO2, 28 de octubre de I6oo.

4. Archivo General de Simancas (AGS), Guerra y Marina (GyM), leg. 566, Relación de los defectos que se allan en las ocho galeras que se labraron en la atarazana de Varçelona en esta ultima fábrica, El conde de Santa Gadea, 3 de septiembre de I60o.

5. AGS, GyM, leg. 567, núm. 135, Relación de don Ramon d'Oms y los maestros mayores de galeras, Barcelona, 30 de octubre de 1600 . 
embarcaciones en los astilleros atlánticos. ${ }^{6}$ Ciertamente, como veremos más adelante, la elección de una u otra opción para la construcción de las galeras tuvo continuidad a lo largo del siglo XVII y parte del XVIII. En I6o8, don Ramon d'Oms fue nombrado capitán general de la escuadra de galeras de Cataluńa, por lo que abandonó su cargo de superintendente de las atarazanas.

Su sucesor en el cargo fue Carlos de Alzate, un veterano con casi quince ańos de servicio al rey en las galeras de Génova, primero, y Nápoles, después. Su padre, don Antonio de Alzate, había servido durante cuarenta y cuatro años al rey y también había sido superintendente de las Atarazanas años antes. ${ }^{7}$ El gobierno de Carlos de Alzate fue difícil, en tanto que tuvo que lidiar con unos virreyes que, en ocasiones, no solo no facilitaron el trabajo de las atarazanas, sino que, además, desviaron los fondos asignados a la construcción naval a otros menesteres e incluso antepusieron sus propios intereses sobre los del astillero -el ejemplo más extremo fue el del virrey, duque de Alcalá, que, literalmente, vació el arca destinada a la construcción de galeras, justo antes de marchar de la ciudad cuando cesó su cargo, en I622. ${ }^{8}$

Tras la muerte de Carlos de Alzate, en I624, la superintendencia de las atarazanas fue encargada a don Bernardino de Marimón, un miembro de la nobleza catalana cuya polémica trayectoria y acciones le aproximaban al bandolerismo que asolaba el Principado. ${ }^{9}$ Además, a diferencia de los anteriores superintendentes, que poseían sólidas trayectorias de servicios en el mar, Marimón apenas tenía experiencia marítima y solo había participado en la expedición de los Querquenes —un grupo

6. Sobre el papel de los asientos en el ejército y en la armada, véase Irving A. A. Thompson, Guerra y decadencia: Gobierno y administración en la España de los Austrias. 1560-1620, Crítica, Barcelona, 198I, pp. 314-335.

7. AGS, GyM, leg. 3146, Madrid, I de octubre de I607.

8. David Goodman, El poderío naval español. Historia de la armada española del siglo XVII, Península, Barcelona, 2006, p. 93. Sobre el dinero que desvió el duque de Alcalá, véase AGS, GyM, leg. 887.

9. Don Bernardino de Marimón llegó, incluso, a refugiarse en Francia para escapar de la justicia del enérgico virrey, duque de Alburquerque. En ElLiotT, La revolta catalana, p. I4I. 
de islotes cercanos a las costas de Túnez- para conseguir galeotes..$^{10}$ Continuamente cuestionada su labor por sus detractores, Marimón llevó a cabo una importante tarea para administrar bien las atarazanas y para que su producción fuera efectiva. Al poco de tomar posesión de su cargo, recorrió los montes del Principado para cerciorarse de su estado y de las posibilidades madereras que ofrecían para la construcción naval; supervisó todas las tareas de tala y extracción de la madera de las montańas y su traslado hasta el astillero, así como se implicó en la producción de las embarcaciones, tratando de responder siempre de la mejor manera posible a las demandas de la Corona. En I633 elaboró un memorial para el cardenal infante, virrey de Cataluńa en ese momento, en el que trataba los aspectos que había que mejorar en la producción de las galeras en aquellas atarazanas y añadía una posible solución para cada uno de ellos."

En primer lugar, pedía que se hicieran nuevos plantíos por la escasez acuciante de álamo, pino y chopo; le seguía la importante falta de maestranza dispuesta a trabajar en las atarazanas, para lo que se aconsejaba subir el salario de los trabajadores y se pedía que se les diera la prerrogativa de gente militar; el tercer punto se centraba más en los aspectos financieros de las atarazanas, para lo que se pedía que el excusado de siete iglesias españolas fuera a parar directamente para las consignaciones de la fábrica de galeras; en cuarto lugar, Marimón recomendaba la compra de cinco bosques situados en el municipio de Santa Coloma de Farners, en los que había muy buenos pinos para las galeras; en quinto lugar, se requería que los diputados acabasen unos arcos que se estaban construyendo en el patio para que se pudiese trabajar en invierno; ${ }^{12}$ el sexto consejo se refería a la reconstrucción del baluarte de las atarazanas, que estaba medio derruido; y por último, aludía a la necesidad de proveerse de astillas para hacer remos. En definitiva, el memorial de don

IO. Goodman, El poderio naval español, p. I8I.

II. ACA, CA, leg. 276, núm. I4, El cardenal infante al rey, Barcelona, io de abril de 1633 .

I2. En este punto, cabe remarcar que eran la Diputación del General y el Consejo de Ciento los encargados de sufragar los gastos de las obras que se realizaban en el edificio. 
Bernardino de Marimón, enviado al Consejo de Aragón, pretendía evaluar el estado en que encontró las Atarazanas de Barcelona cuando se hizo cargo de su gobierno y aquellas deficiencias que había que subsanar.

Don Bernardino de Marimón encabezó, junto con sus hijos, la facción más cercana a la corte y, en todo momento, actuó como un agente de la Corona en el Principado. Por tanto no es de extrańar que, cuando estalló la revuelta de los segadores — que culminó con el asesinato del virrey, conde de Santa Coloma—, Marimón y sus hijos, tras abandonar a la desesperada las propias atarazanas de la ciudad, se encontraran entre los primeros exiliados que se refugiaron en la corte, a la espera de que la situación en el Principado se calmase. Sin embargo, esto no ocurrió y Marimón tuvo que conocer en el exilio la noticia del secuestro de su casa y sus bienes. Por eso, ante la previsión de una estancia fuera de Cataluña más larga de lo que se esperaba, don Bernardino de Marimón solicitó al rey la concesión de algún oficio, y este le otorgó el de administrador general de millones para la provincia de Extremadura. Marimón nunca pudo regresar a Barcelona y murió en el exilio. Su familia, que se quedó en Castilla hasta la finalización del conflicto, solicitó al rey la concesión de mercedes para poder subsistir, dada la pobreza con la que vivían allí y debido a que su patrimonio se hallaba secuestrado por los rebeldes.

Poco o nada se sabe de cómo afectaron a las atarazanas los años de la revuelta y guerra de separación del Principado. Justo en el momento en que estalló el conflicto, en ellas se estaban construyendo tres galeras, embarcaciones muy necesarias dada la situación de guerra que enfrentaba a la Monarquía con Francia, en el contexto de la guerra de los Treinta Años. El 4 de septiembre de I640, el Consejo de Ciento ordenó que se inventariara todo el material, sobre todo el de guerra, que había en el astillero - las atarazanas también servían de arsenal desde hacía algún tiempo-, a efectos, según decía, de tenerlo custodiado en servicio del rey y evitar que lo pudiesen robar. ${ }^{13}$ Pese a las objeciones puestas

I3. Archivo Histórico de la Ciudad de Barcelona (AHCB), Armades i port, Inventari de les coses tretes de la Drassana. 
por Diego Sistero, veedor del rey en el Principado, y Gabriel Gatuelles, mayordomo de la artillería y tenedor de bastimentos de las atarazanas, los oficiales del Consejo de Ciento sacaron las armas y la pólvora del arsenal, que se repartieron, más tarde, entre el pueblo y el ejército. Sin embargo, la pregunta que conviene realizar aquí es si hubo o no producción de galeras durante el período bélico. La respuesta es que no la hubo. Sí que se realizó una sustitución en los cuadros de mando de las atarazanas, tanto en la superintendencia como en la oficialidad, lo que indica que había una voluntad de seguir fabricando embarcaciones. Pero, en realidad, excepto alguna pequeña embarcación hecha en el astillero - una falúa_, la producción durante la guerra quedó estancada. Las atarazanas sirvieron de prisión para los soldados castellanos capturados en batalla. ${ }^{\mathrm{I}}$ Así, desde enero hasta marzo de I642, tan solo doce guardias custodiaron a más de cuatrocientos combatientes allí recluidos. ${ }^{\text {I5 }}$ Del mismo modo, en el dietario de la Diputación del año I645, se anotó que, tras la batalla de Balaguer, en apenas tres días entraron presos en las atarazanas cerca de dos mil soldados del ejército real. ${ }^{16}$ Todo parece asegurar que las atarazanas estuvieron repletas de prisioneros de guerra y, posiblemente, en unas condiciones de hacinamiento bastante deplorables.

Tras la guerra, el edificio se mantuvo inoperativo durante algunos años. Iniciados los trabajos de reconstrucción, se planteó en la corte la posibilidad de levantar en él un cuartel para alojar caballería y soldados $\mathrm{y}$, de este modo, poder librar a la ciudad de los detestables alojamientos de tropas. ${ }^{17}$ La ciudad había aceptado colaborar económicamente en la edificación de este cuartel, para lograr a cambio la devolución del control de las puertas de la ciudad y conseguir recuperar el gobierno ante-

I4. Francesc Carreras CANDi, Les Dreçanes barcelonines: sos inventaris i restauració, Tàber, Barcelona, I928, p. 26.

I5. AHCB, Armades i ports, IC. VII-24, ff. I-IO.

I6. Dietaris de la Diputació del General, dir. J. M. Sans i Travé, Io vols., Generalitat de Catalunya, Barcelona, 2000, vol. vi, pp. 79 y 80, 27 y 30 de junio de I645.

I7. ACA, CA, leg. 2I6, núm. 3, El Consejo de Aragón al rey, 9 de septiembre de I66I. 
rior a la guerra. Sin embargo, el plan de la monarquía, lejos de limitarse a erigir un cuartel para tropas, era fortificar las atarazanas: fundar una verdadera ciudadela para controlar a la población y evitar nuevas revueltas, cuando todavía estaban candentes las ascuas del anterior conflicto. La idea de los ministros del rey era clara: construir un «quartel seguro y cerrado que se ha de hacer en el Taraçanal para ssegurar essa ciudad de qualquiera accidente popular y aliviarla del alojamiento de soldados». ${ }^{18}$ La negativa de los barceloneses se basaba en el incumplimiento de la promesa realizada en su momento por don Juan José de Austria de que debía «hazer la Ciudad un cubierto y avitacion para la gente de guerra y no otra cosa».19 Finalmente, se desaconsejó la fortificación de las atarazanas y se desestimó el proyecto.

Mientras duró la revuelta catalana, la Monarquía española tuvo que construir sus galeras en los astilleros de Génova. Así lo expresaba la Junta de Galeras al rey, en I66r: «desde la solevación de Barcelona todos los buques de galeras que se an fabricado de nuevo se an hecho en Genova». ${ }^{20}$

Dado que, al realizarse la maniobra de la botadura de los buques, estos carecían aún de cualquier tipo de bastimentos, arboladuras o pertrechos, era necesario que fuesen remolcados por otra galera para, posteriormente, dotarlos de todo este equipamiento. Por eso, había que remolcar hasta Barcelona los buques botados al agua en Génova para, una vez allí, armarlos y bastimentarlos. Y claro está, esta maniobra de remolque era peligrosa, dado que debían atravesar el golfo de León, cuyos temporales eran de una agresividad importante — por no hablar de la posibilidad de algún ataque de embarcaciones francesas, turcas o bereberes_- Así que dados los problemas que conllevaba la fabricación de los buques en Génova, y una vez desechada la idea de fortificar las atarazanas, se comenzó a fraguar el proyecto de reabrir los astilleros barceloneses. Así, ya en I653, el marqués de Castel Rodrigo, virrey de

18. Ibidem.

19. Ibidem.

20. AGS, GyM, leg. 3444, La Junta de Galeras al rey, Madrid, I4 de enero de I66I. Citado por Goodman, El poderío naval español, p. I93. 
Cataluña, inició el corte de maderas para conducirlas a las atarazanas y expresó su voluntad de que se desplazasen a Barcelona los hermanos Salinero, ${ }^{21}$ dos reputados maestros italianos de hacer galeras, cuyos saberes y experiencia en la materia se quería aprovechar ahora en la ciudad. Sin embargo, tras frustrarse el plan de traer a los Salinero, se llamó de nuevo al maestro mayor de hacer galeras de las atarazanas de Barcelona, Gerónimo Verde, el cual, tras el estallido de la guerra en Cataluña, se desplazó a Cartagena. Sin embargo, además de la peligrosidad de remolcar los buques sin arboladura hasta Barcelona, la Junta de Galeras argumentaba otra causa, según opinión de expertos como el marqués de Bayona, para reabrir el astillero catalán: la mala calidad de las embarcaciones hechas en Génova:

Con esta ocasión representa la mala calidad de la fabrica del Tarazanal de Genova y su gran costa por deverse volver hazer las obras muertas aunque sea en buques nuevos, su poca duracion, quando los fabricados en Barcelona pasan de 20 ańos y pone en la real consideracion tantas conveniencias de hacienda y buena razon de estado aora que se prefiera a la de Genova y la Capitana es de tan flaca fabrica que será necessario mudarla de aquí a quatro o cinco ańos [...] Representa [el marqués de Bayona] a $\mathrm{V}$ Mgad. que siendo preciso fabricar estos tres buques tendrá gran conveniencia que se hagan en Barcelona. ${ }^{22}$

A tenor de estas palabras, entendemos que en ciertos sectores de la armada y de los ministros de la corte se creía que las galeras fabricadas en Génova eran de peor calidad que las construidas en Barcelona. Esta opinión se encuadra en el debate existente a lo largo de todo el período estudiado sobre la conveniencia de construir las galeras por administración o darlas por asiento, como comprobaremos más adelante. Los cierto es que, a mediados de 1664, el rey decidió que estas tres galeras se fabricasen en Barcelona, lo que supuso el reinicio de la actividad fabril de las atarazanas de Barcelona. Pero antes se debía recuperar la estructura de mando y de

2I. AGS, Estado (E), leg. 3286, núm. I79, El Consejo de Estado al rey, Madrid, I6 de julio de I663.

22. AGS, GyM, leg. 3352, La Junta de Galeras al rey, Madrid, 23 de abril de 1664. 
trabajo. Para lo segundo, como ya se ha dicho, se llamó de nuevo a Gerónimo Verde, maestro mayor; mientras que para lo primero se nombró superintendente a don Juan de Marimón, hijo del ya fallecido don Bernardino de Marimón. A partir de este momento, la superintendencia de las atarazanas recayó en un miembro de esta familia, lo que supuso una patrimonialización del cargo, pese a que siempre había sido una elección del rey entre una terna de candidatos presentada por el virrey a los consejos de Aragón o de Guerra, según la circunstancia y el momento.

Poco se conoce de la actividad de las atarazanas durante las décadas siguientes de I670 y I680. La producción de galeras estuvo muy condicionada por la falta de dinero, lo que provocó la reducción drástica de las escuadras, debido a la imposibilidad de reponer los buques o carenar los viejos. Con todo, las atarazanas experimentaron algunos repuntes de producción, coincidentes con los conflictos armados en los que la Monarquía se vio envuelta. Además, en muchas ocasiones, la actividad fabril de las atarazanas chocaba con las constituciones del Principado y con algunas actividades económicas de los naturales del país. En concreto, las necesidades madereras de la construcción de galeras se veían perjudicadas por una serie de acciones que don Félix de Marimón denunció en un memorial de I673: la exportación de madera, sobre todo a Francia, donde se utilizaba en la fabricación de barcos para luchar contra la Monarquía Hispánica; la explotación forestal para hacer brea, alquitrán y otras materias, algunas de ellas imprescindibles para la construcción naval, o la difusión de las carboneras, que consumían gran cantidad de madera, entre otras, generaban la escasez de materia prima para las atarazanas. ${ }^{23}$ Ante el requerimiento del superintendente, el duque de Sessa, virrey y capitán general de Cataluña, trató de poner límite a estas prácticas emitiendo un bando que prohibían estas acciones, en especial, la saca de maderas para Francia. ${ }^{24}$ Las medidas generaron una polémica con las autoridades del Principado. En primer lugar, por

23. ACA, CA, leg. 204, núm. 68, El Consejo de Aragón a la reina regente, Madrid, 2 de enero de 1673 .

24. ACA, CA, leg. 204, núm. I/80, Crida hecha en Barcelona el 30 y 3 I de enero de 1673 . 
el bando emitido, ya que se hizo en nombre del capitán general y las constituciones no permitían que la Capitanía General emitiera bandos públicos. ${ }^{25}$ En segundo lugar, porque las prohibiciones reflejadas en el bando eran, según la Diputación del General, inconstitucionales, por cuanto limitaban los derechos de acción de los catalanes. Sin duda, en esta etapa en que los catalanes trataron de aferrarse a su corpus legal para recuperar la situación política anterior a la guerra de separación, las demandas y necesidades del virrey para satisfacer las órdenes de la Monarquía en cuanto a construcción de galeras en las atarazanas no encontraron una buena acogida entre las instituciones de la tierra que, como hizo la Diputación del General, las consideraron «contrafacción». ${ }^{26}$

Por el contrario, disponemos de bastante documentación para reconstruir la historia de las atarazanas durante la última década del siglo XVII, gracias a la correspondencia mantenida por el superintendente don José de Marimón y los diferentes oficiales y ministros de Madrid que tenían jurisdicción en la materia: entre otros, el presidente del Consejo de Cruzada y los secretarios del Consejo de Guerra y del Despacho Universal. El análisis de esta correspondencia nos permite afirmar que las atarazanas prosiguieron su actividad hasta el estallido de la guerra de sucesión. Así, en 1703 se estaban construyendo en el astillero dos galeras: una patrona y una sencilla. ${ }^{27}$ Únicamente se vio alterada la producción durante los asedios franceses de I69I y I697, cuando los bombardeos galos obligaron a suspender la actividad fabril.

Con el estallido de la guerra y la llegada a Barcelona del archiduque Carlos, se produjo, como en el caso de la pasada guerra de los Segado-

25. Constitutions fetes per la S. C. R. Magestat del rei don Phelip Segon, Rey de CasteIla, de Aragó, En la primera Cort celebra als cathalans en la Ciutat de Barcelona en lo Monastir de St. Francesch en lo any 1599, Capítulo de Corte, núm. 9.

26. Dietaris de la Generalitat, vol. VII, p. 556, 22 de febrero de i673. También en ACA, CA, leg. 204, núm. I/85, Los diputados de Cataluña al virrey, duque de Sessa, sin fecha.

27. Archivo del Museo Naval de Madrid, leg. I278, exp. 59, Don José de Marimón al secretario Francisco Rodríguez de Mendarosqueta, Barcelona, I de diciembre de 1703 . 
res, una sustitución de cargos y oficiales en las atarazanas. Muy poco, por no decir nada, sabemos de la historia de las atarazanas durante el episodio bélico. Sin embargo, a diferencia de lo ocurrido tras la revuelta catalana de I640, una vez recuperada la ciudad de Barcelona para la monarquía de Felipe V, las atarazanas retomaron su actividad pocos meses después. Comenzó entonces el último período de construcción naval en el astillero barcelonés, que finalizó en I746, con el real decreto del rey por el que suspendía la construcción de galeras en Barcelona y ordenaba que tanto la maestranza como los materiales se enviasen a Cartagena. Durante los treinta años de producción del astillero en el siglo XVIII, se continuó con la dinámica de construir buques para sustituir los antiguos; si bien, la producción respondió a las necesidades navales de la política exterior de Felipe V. La orden real de I746 truncó definitivamente una tradición constructiva naval de siglos y dejó el edificio en manos del arma de artillería.

\section{La financiación de la institución}

Un tema crucial para entender la historia y el funcionamiento de las atarazanas de Barcelona es el de su financiación. ¿Quién pagaba y de dónde salían los caudales para sufragar la construcción de galeras? La fecha clave de la que hay que partir para analizar esta cuestión es 1562, año en que el papa Pío IV concedió al rey católico la bula de la Santa Cruzada para ayudar a costear la lucha contra los infieles musulmanes y el subsidio, es decir, una cantidad de 420.000 ducados, situados sobre las rentas eclesiásticas de Espańa, para sustentar una escuadra de sesenta galeras que defendiera la cristiandad de la amenaza turca. ${ }^{28}$ Estos dos impuestos, junto con el excusado, fueron la fuente financiera de las galeras. En I603, tras la renovación de las bulas por parte del papa Clemente VIII, Felipe III reorganizó la administración del dinero recaudado y destinado

28. Thompson, Guerra y decadencia, p. 23. 
para la construcción y sustento de las galeras. ${ }^{29}$ Con ello pretendía agilizar el cobro y la distribución del caudal para que llegase a tiempo a los pagadores reales que estaban repartidos por los diversos puertos de la Monarquía. Para la fábrica de buques en las Atarazanas de Barcelona se estableció una consignación de 20.000 ducados anuales, provenientes del producto de las Tres Gracias — cruzada, subsidio y excusado- Sin embargo, como a menudo informaban los oficiales de las atarazanas, este dinero, llegaba tarde y en pocas cantidades. Y tenían razón los oficiales, porque se produjeron muchos problemas a la hora de cobrar el subsidio y el excusado del Reino de Aragón y del Principado de Cataluña. El retraso en la llegada del dinero a las arcas del astillero provocó, a su vez, la demora en los procesos de la producción fabril, en especial en la tala de maderas, que se debía hacer en determinadas épocas del año.

Por otro lado, en la producción de galeras la Monarquía también dudó entre otorgarla al capital privado, es decir, a los asentistas, o continuar con la producción mediante administración. Y este debate se encontraba directamente relacionado, está claro, con los costes de producción de las galeras en el astillero barcelonés. En I635, el marqués de Valparaíso, miembro de la Junta de Reformación, opinaba que el coste de los buques de galera que se fabricaban en Barcelona era excesivo. Según decía, cada galera costaba I3.388 escudos en plata, "cosa muy exorbitante porque no cuestan mas de 45.000 reales y por eso era conveniente atajarlo dando la construcción de las galeras por asiento». ${ }^{30}$ Sin embargo, el Consejo de Estado y la Junta de Galeras desmintieron las cantidades expuestas por Valparaíso, ya que en ellas se incluían otros muchos gastos que no eran propios de la construcción de los buques, como pueden ser los bastimentos y pertrechos, jarcias, arboladuras, munición, provisiones o remeros, cuyas cuentas no debían incluirse en las de las atarazanas. Contra la opinión de Valparaíso, el marqués de Villafranca, don García de Toledo, capitán general de las galeras de España, era favorable a continuar la construcción de galeras por administración:

29. AGS, GyM, leg. 579, núm. 487, El rey al comisario general de Cruzada, Valladolid, 4 de abril de 1603 .

30. AGS, GyM, leg. I3IO, La Junta de Galeras al rey, Madrid, 28 de febrero de I635. 
Costa mayor es a V Magd. que una galera le cueste a su Real Hazienda quatro mil ducados, y que dure cinco u seis ańos, pues al cabo dellos, se a de barar otra y las dos importaran ocho mil, y oy en la fabrica, que por administracion se gobierna, duran las galeras doce y trece, y cuando cuesten algo mas que el precio ordinario de las de asiento, sirben otro tanto que ellas, y assi es aorro lo que pareçe crecimiento de gasto, a que debe añadirse que para nabegar en las Mares de Poniente [donde las galeras de España lo hacen] no son aptas las fabricas flacas, hechas por asiento, tanto por las mares gruesas como por los remolcos de navíos de Indias, barras en que cada dia tocan, y mareas, sobre que laboran cada seis horas. ${ }^{31}$

Pese a que, en la mayoría de las ocasiones, la fabricación de galeras continuó por administración, en algunas otras se dieron asientos para construirlas en el astillero catalán, sobre todo durante la última década del siglo XVII y durante el siglo siguiente. Sin embargo, las autoridades tuvieron muchos problemas para encontrar candidatos que pujaran para hacerse con el asiento. En no pocas ocasiones, fueron los propios oficiales de las atarazanas quienes se quedaron con el asiento para construirlas. Con todo, podemos constatar que se produjo una nula presencia de genoveses u holandeses en la contratación de estos asientos, lo que contrasta con la importante presencia de los primeros en los asientos de sustento de galeras y de los segundos en la construcción de navíos para la flota atlántica. Según afirmaba el marqués de Villafranca, si los genoveses se quedasen con los asientos para la corta de la madera destinada a la construcción de las galeras acabarían rápido con los montes, ya que utilizarían y exportarían la madera para otros fines. ${ }^{32}$ Paradójicamente, sí encontramos la participación de genoveses en la construcción de navíos en Cataluña; prueba de ello es el asiento de Nicolás Judice Fiesco para fabricar ocho galeones y un patache en Arenys de Mar, en I622.33

3I. AGS, GyM, leg. I3ıo, Don García de Toledo al rey, Barcelona, 27 de enero de 1635 .

32. Ibidem.

33. AGS, GyM, leg. 887, Nicolás Judice al rey, Barcelona, 5 de noviembre de I622. 


\section{La producción}

Durante las dos últimas décadas del siglo Xvi, la Monarquía, obligada por la falta de recursos económicos y materiales, cambió su concepción de las armadas de galeras. ${ }^{34}$ Se dejaron atrás las grandes escuadras de galeras de la época de Lepanto y de los años inmediatamente posteriores, como la de Espańa de treinta o cuarenta buques, para hacer escuadras más pequeñas y ágiles, de entre diez y dieciocho galeras como mucho, y sobre todo más baratas. No volverán a verse escuadras con más de veinte galeras. Así, en un informe del Consejo de Guerra, de I62I, se deja claro que debido a la reducción de las escuadras a doce galeras se habrán de fabricar menos en las atarazanas de Barcelona. ${ }^{35}$ De este modo, a lo largo de los siglos XVII y XVIII, la producción de galeras se limitará en gran medida a fabricar buques que habrían de reemplazar a los ya existentes que no estuvieran en condiciones de navegar y de soportar la campańa siguiente —eso sí, aprovechando de los buques viejos todos aquellos materiales servibles y reutilizables en los nuevos-. Por eso se destinarán más recursos para el carenado o aconcho de las galeras, actividad que normalmente se llevaba a cabo en el puerto de Cartagena o en el puerto de invernada de cada escuadra.

Aun así, la producción de galeras también quedará condicionada por la capacidad constructiva de las atarazanas y de la maestranza disponible en ellas. En el primero de los casos, la producción de galeras en las atarazanas tendrá una seria competencia, en cuanto a espacio disponible en el edificio, con el arsenal de artillería que, desde la segunda mitad del siglo XVII, se custodiaba en él. Fue durante los primeros años del siglo XviII cuando se agravó la situación, puesto que el arma de artillería ocupaba

34. Sobre el estado de la navegación en el siglo xvi, véase Miguel Ángel BunEs IBARRA, «La defensa de la cristiandad; las armadas en el mediterráneo en época moderna», en Cuadernos de Historia Moderna. Anejos: Armar y marear en los siglos modernos (XV-XVIII), V (2006), pp. 77-99; y Pedro Fondevila Sirva, «Tipología de las galeras españolas del siglo xVI», Revista de Historia y Cultural Naval, IIO (2010), pp. $25-52$.

35. AGS, GyM, leg. 3147, El Consejo de Guerra, Madrid, 3 de diciembre de I62I. 
un gran número de arcos, de manera que se limitaba la construcción de galeras. En cuanto a lo segundo, las atarazanas de Barcelona presentaron una falta acuciante de maestranza a lo largo de todo el siglo xvir, lo que imposibilitó el incremento de la producción cuando así lo requerían las necesidades militares de la Monarquía. Estas carencias quedan muy bien reflejadas en una consulta del Consejo de Guerra, de mediados de i6o8:

Por todo el año que viene estaran a punto de varar quatro galeras y que ay ocho arcos capazes para fabricar otros tantos bucos, y que en caso de necesidad forzosa se podrian fabricar otros ocho en un patio que ay descubierto en las mesmas Atarazanas, pero que con los pocos maestros daxa que ay no se podran fabricar en un año mas de seys galeras. ${ }^{36}$

En el Anexo I aportamos algunos datos cuantitativos de las galeras construidas en las atarazanas. Entre 1600 y I602, por ejemplo, se botaron al agua once buques. Y el superintendente Carlos de Alzate decía en un memorial que, bajo su mandato, se habían construido en las atarazanas entre 1607 y I6I7 quince galeras y cinco bergantines. ${ }^{37}$ La escalada bélica que se inició en la década de 1620 — que desembocará en el estallido de la guerra con Francia en I635- generó un repunte de la producción, ahora ya bajo las órdenes del superintendente don Bernardino de Marimón. Así, ese mismo ańo se ordenó la fabricación de una "armadilla», compuesta de diez fragatas y otros barcos menores..$^{38}$ En la década de I660, se reabrió el astillero ante la necesidad de hacer tres galeras nuevas y una falúa real para que Margarita Teresa de Austria embarcase y desembarcase de la galera real durante su viaje a Italia, para proseguirlo por tierra hasta Viena, donde se encontraría con su esposo, el emperador Leopoldo. ${ }^{39}$

A lo largo de las siguientes décadas, la producción fue escasa, y apenas superó en contadas ocasiones las dos galeras botadas anuales

36. AGS, GyM, leg. 3I46, El Consejo de Guerra al rey, I6 de agosto de I608.

37. AGS, GyM, leg. 825, Carlos de Alzate al rey, Barcelona, 9 de septiembre de I6I7.

38. AGS, E, leg. 2656, El duque de Cardona, virrey de Cataluña, al rey, Perpiñán, 29 de abril de 1635 .

39. AGS, GyM, leg. 3552, El rey a don Vicente Gonzaga, virrey de Cataluña, 3I de agosto de I664. 
-el duque de Sessa informaba de que, durante su virreinato en Cataluña (I669-I673), se habían fabricado en el astillero dos galeras ordinarias, una galera capitana y una galera patrona-.$^{40}$ Ya en el siglo XviII, la producción fue similar a la de los años anteriores al conflicto bélico, y se varaban una o dos galeras anuales. En definitiva, las Atarazanas de Barcelona tuvieron una producción continua, pero siempre con escasos índices cuantitativos, condicionados en la mayoría de las ocasiones por las dificultades hacendísticas la Monarquía.

\section{Técnicas de construcción}

Poco se sabe sobre las técnicas constructivas que se emplearon en la fabricación de galeras en las Atarazanas de Barcelona. Es difícil encontrar en la documentación referencias sobre ello. Durante el siglo XviI aparecieron en España algunos tratados de construcción naval, pero en ellos apenas se hace referencia a la fábrica de galeras, con la excepción de algunas referencias aisladas, pues era su objetivo la construcción de navíos de alto bordo. ${ }^{41}$ Sí que encontramos mucha literatura al respec-

40. AGS, GyM, leg. 2286, La Junta de Galeras a la reina regente, Madrid, 28 de julio de 1673 .

4I. Entre los tratados de construcción naval realizados en España en el siglo XVII destacamos el del capitán Tomé CANO, Arte para fabricar, fortificar y aparejar naos de guerra, y merchante; Con las Reglas de Archearlas: Reduzido a toda Quenta y Medida: y en grande utilidad de la Navegacion, impreso por primera vez en Sevilla en I6II; y el del también capitán Antonio de Gaztañeta, Arte de fabricar reales, Execucion de la Capitana Real, Almiranta Real y otros bageles de guerra y marchante, manuscrito de i688. Sobre técnicas de construcción naval, véase José Luis Casado Soto, «Política naval y tecnología en el mundo mediterráneo», en H. O’Donell y Duque de Estrada, E. García Hernán, J. M. Blanco Núnez, coords., Historia militar de España, 9 vols., Laberinto, Madrid, 2009-20I7, vol. III, t. I, 20I2, pp. 283-315. Del mismo autor, "Aproximación a la galera española en el Mediterráneo durante la época de Felipe II", en E. Belenguer Cebrià, coord., Felipe II y el Mediterráneo, 4 vols., La monarquía y los reinos, Sociedad Estatal para la Conmemoración de los Centenarios de Felipe II y Carlos V, Barcelona, 1999, vol. IV, pp. 33I-348. 
to, en cambio, en Francia, durante ese mismo período, verdadero siglo de oro de las galeras galas en el Mediterráneo. ${ }^{42}$

Lo que queda claro es que la dirección de la actividad constructiva de hacer galeras recaía en los maestros mayores. Ellos conocían la técnica y, lo más importante, las medidas —o gálibos — adecuadas para llevar a cabo la construcción. Los maestros mayores eran celosos guardianes de estas medidas, sobre cuyo secreto descansaba su futuro profesional y el de su familia. También sabían qué tipo de madera aplicar para cada parte del buque, por lo que ellos mismos participaban en las tareas de tala y transporte de los árboles, supervisando el trabajo. El proceso se iniciaba con la colocación de la quilla, vértice desde el que se construía toda la embarcación. Dependiendo de las dimensiones de la quilla, el maestro mayor establecía las medidas del buque. El tamaño dependía del tipo de galera que se iba a construir - por poner un caso, la galera capitana de escuadra tenía unas dimensiones superiores al resto de las galeras-. Además, influían en el tamaño las tendencias y gustos del momento. Por ejemplo, en los primeros ańos del siglo XVII se impuso entre los oficiales de la Monarquía la idea de construir barcos más pequeños y móviles que los que se fabricaban en las últimas décadas del siglo anterior. En las galeras, esto afectaba sobre todo a las galeras capitanas y patronas, cuyo tamaño se consideró excesivo a partir de ese momento. En I606, la Junta de Galeras informaba al rey de la opinión del duque de Feria sobre el tamańo de las galeras:

En Consejo de Estado se ha visto una carta del duque de Feria para Su Magestad de 12 de noviembre en que refiere que siempre ha sido de parecer que las galeras capitanas de las esquadras se reduzgan a menores baxe-

42. Entre los tratados franceses, destacamos el del tesorero general de la Marina de Levante, Ithier Hobier, De la construction d'une gallaire, et de son equipage, aparecido en París, en 1622, y el del superintendente de Marina, señor de Dassie, L'Architecture navale, contenant la maniere de construiré les Navires, Galeres et Chaloupes, et la Definition de plusieurs autres especes de Vaisseaux, publicado en Paris, en I677. Sobre la construcción de galeras en Francia véase André Zysberg, Marseille au temps du Roi-Soleil: La ville, les galères, l'arsenal I660-I700, Jeanne Laffite Editions, París, 2007. 
les pareciéndole que lo demás es ostentación y comodidad en destrucción de toda la esquadra. ${ }^{43}$

En conjunción con las técnicas constructivas, debemos prestar atención a otras actividades que formaban parte del proceso. Una de ellas es la botadura de los buques. Era necesaria la intervención de otras galeras para ayudar a varar las nuevas del astillero. Dado que no tenían remos ni arboladura, la mejor solución para echar la galera al agua era el remolque. En la tarea participaban los oficiales de las atarazanas y de las galeras, cuyas relaciones no siempre fueron cordiales, lo que dificultó la colaboración en el varado.

\section{Los materiales: la madera.}

Uno de los aspectos que más preocupó a las autoridades encargadas de la construcción de galeras fue el de los suministros de materia prima, en especial la madera. Su extracción de los bosques catalanes era cara y dificultosa: una buena partida del presupuesto para construir las galeras se lo llevaba esta actividad. Además, la tala de los árboles solo se podía hacer en determinadas épocas del ańo, marcados por las fases de la luna. ${ }^{44}$ Por eso, como se ha dicho, la falta de caudales podía demorar la corta y el transporte, y las consecuencias eran entonces el retraso en las tareas de fabricación y, más grave todavía, la incertidumbre acerca de si se podrían varar las galeras a tiempo de que pudieran ser utilizadas en la campaña.

En general, los oficiales de las atarazanas preferían la madera de proximidad, es decir, proveniente de los montes cercanos a Barcelona. Sin embargo, tras siglos de explotación y roturación, en ellos apenas quedaban árboles apropiados para la construcción naval. En época moderna, fueron dos las principales zonas extractivas de madera para el astillero: los montes de Tortosa, donde se talaban pinos negros de gran

43. AGS, EST, leg. 458, El Consejo de Estado al rey, marzo de I606.

44. Goodman, El poderío naval español., p. I6I. 
calidad — también conocidos como «pino de melis»—, y una extensa zona que abarcaba el Vallés, la sierra del Montseny y la Selva, de donde se extraían robles, encinas, pinos, entre otras especies. El conservador de montes y plantíos, el superintendente de las atarazanas y los maestros mayores de galeras inspeccionaban los bosques en busca de árboles apropiados para construir galeras. Los seleccionados eran marcados para indicar que eran propiedad del rey, lo que impedía su tala al resto.

La conducción de las maderas a las atarazanas era, quizá, la tarea más costosa. En primer lugar, había que sacar los troncos talados de los bosques, tarea a menudo muy dificultosa por las nieves que caían en invierno, época de la tala. Después eran trasladados con carretas hasta los puertos de embarque. Las constituciones de Cataluña establecían la obligatoriedad de los propietarios de carretas a participar en el transporte de la madera hasta las atarazanas, ${ }^{45}$ lo que provocó no pocas fricciones entre estos y los oficiales de los astilleros, debido a que los primeros tenían que abandonar su trabajo durante días para llevar los troncos hasta Barcelona. En I6I9, más de setecientos campesinos de las universidades del Campo de Tarragona protestaron por la obligatoriedad de remolcar la madera a las atarazanas, a veces con distancias de más de 25 leguas, lo que les suponía dejar su casa y su trabajo por entre diez y quince días. ${ }^{46}$ Dependiendo del bosque de procedencia, las maderas se movían hasta los puertos de Palamós, Blanes o Tortosa, donde se embarcaban para ser transportados hasta las atarazanas.

\section{La maestranza}

Como ya hemos apuntado, el superintendente de las atarazanas constituía la cúspide de la estructura de trabajo del astillero. Él era el brazo

45. Constitutions fetes per la S. C. R. Magestat del rei don Phelip Segon, Rey de Castella, de Aragó, En la primera Cort celebra als cathalans en la Ciutat de Barcelona en lo Monastir de St. Francesch en lo any I599, Capítulo de Corte, núm. 48.

46. ACA, Real Cancillería, reg. 4.90I. Véase Goodman, El poderío naval español, p. 192. 
ejecutor de las órdenes que llegaban de la corte y era él también quien supervisaba todos los procesos productivos de la construcción de galeras, desde la tala de los árboles hasta la botadura de los buques, una vez ya finalizados. Fuera de la estructura de trabajo, estaba el conservador de montes y plantíos, cuya función era inspeccionar los bosques catalanes y seleccionar los árboles adecuados para la construcción naval. ${ }^{47}$ Él mismo estaba presente en la tala de los árboles, en la que normalmente también se encontraban el superintendente y el maestro mayor de galeras. Este último era el oficial de mayor rango dentro del astillero, y disfrutaba de gran prestigio porque conocía la técnica y las medidas para construir la galera.

A finales del siglo XVI, en las Atarazanas de Barcelona actuaban cuatro maestros mayores; sin embargo, a partir de las Cortes de 1599, se estableció que fuera solo uno el maestro mayor, lo que otorgó mayor poder a este. Durante buena parte del siglo XVII y la primera mitad del XVIII, este cargo recayó en un miembro de la familia Verde, con lo que la historia de las atarazanas en esta época está íntimamente relacionada con la historia de dos familias: los Marimón y Verde. Bajo el mando del maestro mayor de galeras se encontraba el resto de oficiales: los maestros de azuela, el maestro calafate, el maestro remolar — especialista en la fabricación de los remos - y el maestro de popas — este ya en época más avanzada - Algunos maestros a menudo gozaban de un entretenimiento que les permitía tener un mayor rango y sueldo. Por último, nos encontramos los maestros de aja y los calafates, encuadrados, muchos de ellos, en su respectivo gremio.

Desde finales del siglo Xvi, las Reales Atarazanas de Barcelona presentaron una falta acuciante de maestranza. La causa principal eran los paupérrimos sueldos que cobraban los oficiales. Así se expresaba en una consulta del Consejo de Guerra de agosto de i6o8:

Según el tiempo que corría y estar las cosas tan caras no se podían sustentar con tres reales que gozan de sueldo al día y que en el Puerto de Santa

47. Sobre la figura del conservador de montes y plantíos, véase Alfredo José Martínez González, Las Superintendencias de Montes y Plantios (I574-I748). Derecho y politica forestal para las armadas en la Edad Moderna, Tirant lo Blanch, Valencia, 20I5. 
Maria, San Lucar y Cadiz y las demas partes donde hay maestranza de galeras les dan a quatro y a cinco reales y de comer. ${ }^{48}$

Ciertamente, a lo largo de todo el siglo xvir, los salarios de los oficiales y trabajadores del astillero continuaron bajísimos, pese a alguna subida muy exigua, concedida a petición de los superintendentes de las atarazanas. Por eso, muchos maestros preferían trabajar para particulares, construyendo embarcaciones o carenándolas. En I633, el secretario del Consejo de Aragón, Juan Lorenzo de Villanueva, escribía sobre la penosa situación de la maestranza de las atarazanas:

La maestranza es tan poca (haviendo sido en tiempos passados tanta) que si Su Mgd. no manda remediarlo, no la habrá dentro de poquissimo tiempo. Que esto lo causa ser corto el jornal, pues no se les da mas de tres reales y medio, y ellos en sus casas los ganan, estando con sus mugeres e hijos. Y en muchas occasiones fabricando algunas saetías y barcas a destajo saliendoles à mucho mas. Que estos estan sujetos a que siempre que se offreçe fabrica en las dichas Atarazanas, se les embia un portero de la Capitanía General, mandándoles con penas vayan à trabajar à ellas, deteniendoles el tiempo que se ofreze, gastando mas que en sus casas, por causa de las sissas y imposiçiones que hay en la Ciudad de Barcelona. ${ }^{49}$

Ante esta situación, los virreyes de Cataluña se vieron obligados a buscar la maestranza en otras partes. Así, en repetidas ocasiones, y coincidiendo con incrementos de la producción por las necesidades bélicas, se reclamó a los virreyes de Valencia y Mallorca que enviasen a Barcelona todos los oficiales calafates y maestros de azuela posibles para construir galeras. Pero estos llegaron en poco número y demasiado tarde para que la construcción de las galeras fuera exitosa. En definitiva, la falta de maestranza constituyó uno de los talones de Aquiles de las Reales Atarazanas, en tanto que su escasez condicionó directamente la producción.

48. AGS, GyM, leg. 3I46, El Consejo de Guerra al Rey, I2 de agosto de I608.

49. AGS, GyM, leg. IO74, Juan Lorenzo de Villanueva, I de agosto de I633. 


\section{Conclusiones}

El presente texto constituye una primera estructuración de lo que será un trabajo de mayor alcance. Sin embargo, la ordenación y vaciado de parte de la documentación ya nos permite exponer algunas conclusiones sobre la historia de las atarazanas. Podemos desterrar la idea preponderante de la inactividad de las atarazanas en época moderna. La documentación ha demostrado que, a lo largo de todo el siglo xvir y durante la primera mitad del xviII, el astillero fabricó buques, a excepción de los dos períodos bélicos. Cabe destacar que la construcción de las galeras dependió directamente de la administración de la Monarquía, salvo en las contadas ocasiones en que se otorgó por asiento. El superintendente de las atarazanas, nombrado por el soberano, ejecutaba las órdenes de las diversas autoridades competentes. Por otro lado, la construcción de galeras en las atarazanas padeció la misma falta de dinero que otras parcelas de la administración militar. La llegada irregular y tarde de las partidas económicas para la construcción de buques condicionó negativamente la actividad y producción de las atarazanas, la cual se agravó, además, por la falta acuciante de maestranza. Sin embargo, pese a todos los obstáculos, el astillero pudo fabricar galeras hasta su definitiva clausura como atarazanas en 1746 . En definitiva, la construcción y buen funcionamiento de una galera era una tarea complicada cuyo éxito dependía de muchos factores en juego: si fallaba uno de ellos, el resto se desajustaba, lo que perjudicaba el desarrollo y la duración de la embarcación. Como dijo Pedro de Leyva, capitán general de las galeras de Sicilia en I622: «una galera deve andar tan concertada para ser de servicio como un relox, que si la falta una rueda no lo es». ${ }^{5 \circ}$

50. AGS, GyM, leg. 887 , Pedro de Leyva al rey, 22 de junio de 1622. 
Anexo

Producción de buques de galeras en las Atarazanas de Barcelona entre 1600 y 1746

\begin{tabular}{|c|c|c|}
\hline Años & Buques & Tipología \\
\hline I600-I60I & II & 9 ordinarias, I capitana y I patrona \\
\hline $1605-1615$ & 27 & I9 ordinarias, 3 capitanas y 5 bergantines \\
\hline I6I6-I6I7 & 5 & 4 ordinarias y I capitana real \\
\hline $\mathrm{I} 62 \mathrm{I}-\mathrm{I} 622$ & 6 & 2 ordinarias, 2 sutiles, I capitana y I patrona real \\
\hline 1627 & 3 & 2 ordinarias y I sutil \\
\hline 1634 & 6 & 4 ordinarias, I capitana y I patrona \\
\hline 1635 & «armadilla» & IO fragatas, 6 «caices» y 6 «barcos luengos» \\
\hline $1638-1640$ & IO & IO ordinarias \\
\hline I666-I668 & 6 & 5 ordinarias y una falúa real \\
\hline I669-I673 & 4 & 2 ordinarias, I capitana y I patrona (en construcción) \\
\hline 1678 & 4 & 4 ordinarias \\
\hline I680-I686 & 9 & 6 ordinarias, I capitana y 2 patronas \\
\hline $1692-1695$ & 5 & 3 ordinarias, I capitana y I patrona \\
\hline 1703 & 2 & I ordinaria y I patrona \\
\hline I7I6-I7I7 & 2 & 2 ordinarias \\
\hline 1723 & 2 & 2 ordinarias \\
\hline 1724 & I & I capitana real \\
\hline 1726 & 2 & I ordinaria y I patrona \\
\hline $\mathrm{I} 728$ & 2 & 2 ordinarias \\
\hline I73I & 3 & 2 ordinarias y I falúa \\
\hline $\mathrm{I} 733$ & 2 & I ordinaria, I capitana y I «barquilla» \\
\hline 1736 & 2 & I ordinaria y I patrona \\
\hline 1743 & 2 & 2 ordinarias \\
\hline I744-I745 & 2 & 2 ordinarias \\
\hline
\end{tabular}

